\title{
LEI, LIBERDADE E DIVERSIDADE DE FINS NO PLURALISMO DE VALORES
}

Ivo Coser é professor associado do Departamento de Ciência Política e do Programa de Pós-Graduação em História Comparada da Universidade Federal do Rio de Janeiro (UFRJ). Rio de Janeiro, RJ, Brasil.

E-mail: ivocoser@uol.com.br

Orcid: 0000-0002-8010-1287

http://dx.doi.org/10.1590/0102-169202/107

\section{Introdução}

Ao longo das últimas décadas consolidou-se nas sociedades contemporâneas o fenômeno da diversidade de concepções de boa vida na cena pública. Seja nos países ditos centrais, seja nos países em desenvolvimento, a emergência da diversidade apresenta-se como um importante tema da agenda política. Um dos traços fundamentais dessa emergência reside no fato de que tais concepções não se sentem representadas no antigo conjunto de valores que organizava o Estado-nação e lutam por reconhecimento e por políticas públicas que atendam às suas demandas. $\mathrm{O}$ estudo da relação entre o pluralismo de valores (PV) e a questão da lei contribui para a discussão desse tema na contemporaneidade. Em razão do seu conteúdo teórico, o PV oferece um aporte teórico valioso para sociedades que experimentam a presença forte de diversas concepções de boa vida na esfera pública.

O principal objetivo deste artigo é discutir os conceitos de lei e de liberdade e seus desdobramentos no PV. Para realizar esse objetivo tomei como base os textos de Isaiah Berlin e de autores que, partindo de sua obra, apresentam outros desdobramentos.

A hipótese deste artigo é que o PV possui uma concepção de lei que engloba não apenas a liberdade 
individual e a segurança do sujeito, mas que visa a proteger e a apoiar a diversidade de concepções de vida. A ideia de incomensurabilidade de fins postulada pelo PV não impede que, a partir de uma razão prática, sejam reconhecidas as características de um determinado contexto histórico político: nessa operação é estabelecida uma classificação não subjetiva dos fins. Dessa forma, é moralmente aceitável que a lei intervenha com o fim de fornecer os meios para os sujeitos exercerem sua liberdade de escolha. Como essa intervenção ocorrerá e quais os valores associados a ela, somente uma deliberação prática poderá estabelecer. O argumento presente na obra de Berlin, e no PV, é interpretado a partir de uma distinção conceitual entre intervenção e obstrução. A lei moralmente aceita é uma modalidade de intervenção que apoia a liberdade de escolha entre fins incomensuráveis; esta, por sua vez, não se confunde com uma obstrução, a qual 170 impede, ameaça ou não fornece os meios necessários de acesso do sujeito aos fins almejados.

Cumpre esclarecer que fiz uso da ideia de lei como distinta da ideia de direitos; essa diferença é mais clara na língua inglesa do que nas línguas de origem latina. Nas línguas de origem latina, droit, diritto e direito são usados sem que haja uma contradição explícita com a ideia de dever, obrigação. Por sua vez, no inglês, o termo right, que pode ser traduzido por "direito" em português, é distinto da ideia de dever (duty). O termo duty remete para o sentido de obrigação, enquanto right denota a opção de fazer ou não fazer tal ato, não devendo ocorrer uma intervenção que obrigue alguém a realizar tal ato (Hart, 1997, p. 282). Na língua portuguesa, no termo "direito" estão presentes dois sentidos. O primeiro seria aquilo que é justo, ou seja, o que é moralmente justo; a partir disso é formulado um conjunto de normas obrigatórias que disciplinam as relações humanas. Um segundo sentido de direito diz respeito 
à faculdade de praticar ou deixar de praticar um ato, consistindo, portanto, em uma prerrogativa que o sujeito possui de praticar ou deixar fazer algo (Buarque de Holanda, 1999; Caldas Aulete, 1958). O primeiro sentido de direito está mais próximo do sentido de lei. Quando observamos o termo "lei", ele não possui a "instabilidade" presente no termo "direito". A lei é definida como a regra ditada pela autoridade legal e tornada obrigatória; domínio, poder, mando. A lei, portanto, consistiria em uma prescrição emanada do poder soberano.

Quando menciono ao longo do artigo o termo "lei" tenho em mente a primeira ideia: uma intervenção feita a partir de normas vinculatórias. A lei, nesse sentido, é entendida como uma ordem para um sujeito geral, não específico, com o sentido de que este faça alguma coisa (Hart, 2012). Ao utilizar-me do termo "intervenção" pretendi ressaltar o aspecto da lei entendida como uma ingerência com o fito de produzir um determinado resultado, ideia distinta, mas não radicalmente diferente, daquela na qual a lei é entendida, principalmente, na sua dimensão de um instrumento que garante direitos, mas que faculta ao sujeito o fazer ou não fazer.

\section{0 pluralismo de valores}

O PV começa a tomar forma ao longo da obra de Isaiah Berlin. Ao longo de sua trajetória intelectual, o autor produziu uma vasta obra abordando temas distintos: teoria política, romantismo, filosofia da história, filosofia da linguagem, nacionalismo e literatura russa, dentre outros. Mas por detrás dessa diversidade de temas emergiu um conjunto de ideias centrais que forneceram uma base teórica posteriormente reunida em um corpus designado "pluralismo de valores" (PV) (Crowder, 2004). Um dos marcos desta última corrente é o ensaio "Dois conceitos de liberdade" (DCL), publicado em 1958 e republicado 
em 1969, revisto, com algumas alterações, precedido de uma relevante introdução na qual Berlin revê alguns conceitos e responde a várias críticas. Os esforços teóricos de releitura desse ensaio procuram colocá-lo em perspectiva com o conjunto da sua obra, apontando sua articulação com os trabalhos tanto posteriores como anteriores. Nesse esforço de integração surge como elemento central o conjunto de ideias presente principalmente na última seção do texto "O um e o múltiplo" (Crowder, 2013), que esteve presente, de diferentes formas, em trabalhos posteriores e que fornece o fio que liga seus diversos trabalhos e inspira autores contemporâneos (Crowder, 2018). A partir desses trabalhos, pode-se postular que o PV possui três ideias-chave: a diversidade de fins, o conflito entre os fins e a incomensurabilidade entre os fins últimos (Berlin 2002b, p. 47-52; Crowder, 2002, p. 2-3).

O PV postula como enunciado básico a ideia de que, 172 na experiência ordinária de homens e mulheres, existe uma diversidade de fins razoáveis, e a realização de alguns deles implica o sacrifício de outros. É em razão desse dado que o PV atribui centralidade à ideia de liberdade de escolha (Berlin, 2002a, p. 269). Tal enunciado corresponde a uma reivindicação de verdade que não pode ser confundida com um sentimento de perplexidade produzido no sujeito, o qual poderia ser suprimido por meio de procedimentos mentais. Nesse sentido, a reflexão teórica do PV corrobora uma experiência imediata dos sujeitos (Galston, 2002, p. 30).

Uma segunda ideia do PV é que os fins últimos são não apenas diversos, mas também não existe uma métrica moral capaz de harmonizá-los. Fins como justiça, bem-estar material, liberdade, segurança, comunidade, autonomia individual, fraternidade etc. não são passíveis de serem hierarquizados sem 
que essa ação implique perdas. ${ }^{1}$ Tal diversidade de fins pode, em certos contextos, provocar não apenas perdas, mas também conflitos entre os fins. Quando o PV menciona o conflito entre os fins tem em mente que eles são fins razoáveis que contribuem para o florescimento humano (Berlin, 2002d). Ou seja, não se trata de um conflito entre fins contrários à humanidade e fins razoáveis, como, por exemplo, um embate entre, de um lado, o extermínio, a mentira e a tortura e, de outro, o convívio pacífico, a verdade e o respeito pelo gênero humano (Gray, 2000b, p. 62-67).

Esse embate ocorre entre fins que são fins em si mesmos, ou seja, que fornecem os critérios a partir dos quais são julgados o certo e o errado, o fracasso e o sucesso e os meios a serem utilizados (Berlin, 2002c, p. 104-106).

Na vida ordinária, ou no plano dos arranjos políticos, na medida em que não é possível encontrar uma hierarquia entre os fins últimos, a diversidade de fins e a liberdade de escolha ganham precedência. Como consequência, os arranjos políticos que asseguram a diversidade de fins e a liberdade de escolha são preferíveis a arranjos políticos que os constrangem ou impedem. Na medida em que os homens e as mulheres se deparam com uma diversidade de fins e estes entram em conflito, o PV confere precedência à autonomia

1 Em sua obra Berlin usa as palavras "fins", "valores" e "metas" sem fazer distinção entre elas. Berlin menciona diversos fins, que são tanto substantivos como morais: igualdade política, eficiência organizacional, justiça social, liberdade individual, justiça como imparcialidade, piedade, precedência da comunidade, privilégios para a criação entendida como manifestação superior, secularização. Esse uso pouco preciso foi discutido por Kekes (1993, p. 18, 39-42), que considerou mais adequado estabelecer uma divisão a partir dos bens almejados por qualquer criatura humana. Ao longo do artigo, optei por manter a imprecisão berliniana; a divisão proposta por Kekes parece-me excessivamente universalista, incorrendo no erro de pressupor que certos valores, como civilização e intimidade, seriam universais (Kekes, 1993, p. 39). Tal equívoco foi sempre evitado pelo argumento berliniano, o que não implica que não haja neste uma tensão entre universalidade - bens que estariam presentes em todas as sociedades - e relativismo moral. Essa tensão esteve presente em vários momentos da obra berliniana (cf. Berlin e Jahanbegloo, 1998, p. 30), sendo objeto de debate entre o próprio Berlin e Crowder (cf. Berlin e Willians, 1994 e Crowder, 2018). 
do sujeito e à diversidade de fins presentes na vida social (Berlin, 2002e).

Essa experiência da vida ordinária gerou na teoria política ocidental duas formas de abordagem dos problemas morais: o monismo e o pluralismo (Berlin, 2005, p. 22-23). O monismo compreende que para as questões políticas existe apenas uma resposta certa, que pode ser encontrada mediante um método adequado: dependendo da corrente teórica ele reside na observação das leis sociais, da consulta de textos sagrados etc. O confronto entre diversas concepções de bem pode ser resolvido pela ideia de que uma concepção representa o falso, a consciência alienada ou a falta de esclarecimento, enquanto outra encarna a realização humana plena que todos os homens e mulheres esclarecidos e conscientes das leis sociais deveriam almejar (Berlin, 2002a, p. 268-269). É exatamente o oposto dessa ideia que orienta a perspectiva pluralista: a inexistência de 174 uma resposta única para os problemas políticos conduz os indivíduos, sob certas circunstâncias, a realizar escolhas trágicas entre estes (Berlin, 2005, p. 51). O conflito não nasce de má-fé ou de uma deficiência epistemológica que pode ser suprimida, mas está inscrito na condição humana (Berlin, 2002b, p. 47).

Discutir a questão da lei no PV permite analisar como essa corrente entende a intervenção legal em uma sociedade marcada pela diversidade. Assim, tomando como base a discussão presente no PV, analiso em seguida três modalidades de intervenção e suas relações com as ideias centrais do PV: a lei como uma obstrução ou intervenção arbitrária, a lei como não interferência e a lei como interferência moralmente aceita.

\section{A intervenção como uma obstrução}

O contexto político no qual Berlin redige DCL foi marcado pela presença de estados ou grupos sociais que, em 
nome de ideais de nação, razão ou história, organizaram aparatos repressivos. Toda uma estrutura jurídica e coercitiva foi montada para disciplinar, impedir, constranger e, eventualmente, torturar os cidadãos em nome desses ideais.

Esse contexto conduziu Berlin a refletir sobre o conteúdo dessa ação. A ideia central consiste no seguinte: quando um sujeito é impedido, intencionalmente ou não, de agir em direção a fins, e esse impedimento contraria noções básicas de justiça e de moralidade, inicia-se a discussão sobre uma obstrução. Da parte do sujeito esse desejo em buscar certos fins é compreendido como uma prerrogativa sua, faz parte do seu direito almejá-los e, na medida em que arranjos políticos são criados ou grupos sociais agem com vistas a impedir o acesso a eles, fala-se de uma obstrução. No ensaio "A ideia de liberdade" (1955), Berlin apresenta a liberdade como uma ação que se desenrola sem a presença de um obstáculo (Berlin, 2009a, p. 149). Em "Dois conceitos de liberdade: o romântico e o liberal” (DCLRL), Berlin define o conceito liberal com o mesmo conteúdo que atribuirá à liberdade negativa. Sua definição reafirma a ideia de que liberdade se caracteriza como ausência de obstáculos (Berlin, 2009b, p. 218).

Caso obstáculos sejam interpostos, a concepção liberal pressupõe que a lei seja um instrumento para impedir o abuso (Berlin, 2009b, p. 217). Dessa maneira, nem toda intervenção é uma obstrução; a lei intervém para coibir ou punir uma obstrução ilegal. Logo, há uma distinção entre uma obstrução frente a um fim moralmente aceitável e uma intervenção legalmente prevista, de maneira a impedir que essa obstrução se manifeste, ou puni-la, caso ocorra. Ambas são formas de intervenção, mas a obstrução é uma intervenção arbitrária, enquanto a lei é uma intervenção moralmente aceitável.

Posteriormente a esses dois ensaios, Berlin apresenta o conceito de liberdade negativa, reafirmando a mesma ideia: 
a liberdade negativa como uma esfera desobstruída. Se outros impedem-me de fazer o que do contrário eu poderia fazer, não sou livre (Berlin, 2002a, p. 229).

Entre os dois ensaios escritos no começo dos anos 1950 e DCL há uma coerência teórica: a liberdade negativa é definida como uma esfera desobstruída. Por sua vez, uma obstrução é entendida como intervenção moralmente inaceitável. Em decorrência dessa ideia, a lei é apresentada como uma intervenção com o objetivo de impedir uma obstrução. A lei e a obstrução são tipos distintos de intervenção. Segue-se que a liberdade negativa é definida como ausência de obstrução, mas não como ausência de intervenção, pois existem modalidades de intervenção moralmente aceitas. A primeira consiste em punir ou prevenir a obstrução; e, para além dessa função da lei como um vigia, existem outras modalidades de intervenção legal moralmente aceitas pelo $\mathrm{PV}$, as quais discutiremos mais adiante.

No argumento de Berlin há três conteúdos por meio dos quais a ideia de obstrução se manifesta. Com relação ao primeiro sentido deve-se destacar que a ideia de coerção ou escravidão presente no seu argumento consiste na ideia de que existem fins almejados pelo sujeito ou pelo grupo que não são alcançados em razão de um impedimento decorrente de uma ação discricionária, que viola as regras morais ou legais com o intuito de controlar esses fins. ${ }^{2} \mathrm{O}$ fato de o grupo ou o sujeito não obterem os fins almejados não é o

\footnotetext{
2 Berlin utiliza-se dos termos coercion e slavery para designar uma ação que segue uma vontade caprichosa de um grupo que visa a preservar para si um determinado bem socialmente importante. Utilizei o termo "arbitrário" e não "coercitivo" porque, para o PV, a lei entendida como uma expressão justa e moralmente aceita também faz uso da coerção, mas com amparo no justo e moralmente aceitável. A coerção deve ser entendida a partir da definição clássica, a capacidade que $\mathrm{A}$ possui de alterar o comportamento de $\mathrm{B}$, a despeito das resistências de B. Também evitei o termo "escravidão" porque o conceito não se aplica apenas a situações nas quais essa condição social está presente. Entretanto, não se deve confundir o uso feito por Berlin e pelo PV com o conceito de arbitrariedade estabelecido pelos neorrepublicanos (para uma confrontação entre o argumento de Berlin e dos neorrepublicanos, cf. Coser, 2014).
} 
resultado da sua incapacidade física ou intelectual, mas da ação que bloqueia o acesso. Em segundo lugar, esses mesmos bens estão disponíveis para outros grupos sociais, aspecto que, perante os olhos do grupo, revela o caráter injusto das leis ou procedimentos informais (Berlin, 2002a, p. 230).

Com esta ideia em vista podemos compreender a conclusão do trecho: "Quanto maior a área de não interferência, mais ampla a minha liberdade" (Berlin, 2002a, p. 230). É fundamental assinalar o momento do ensaio DCL no qual Berlin apresenta essa ideia, de maneira a que não se considere que ela se refere a qualquer forma de intervenção. Berlin apresenta essa conclusão no bojo de um raciocínio sobre obstrução; não se trata de qualquer modalidade de intervenção, mas apenas aquela que siga o modelo descrito anteriormente. Neste sentido, e apenas nesse sentido, quanto maior a área não sujeita a uma intervenção (ou, com o termo aqui proposto, "obstrução"), maior a liberdade.

Essa modalidade de obstrução pode fazer uso daquilo que Berlin designa como paternalismo despótico. Nessa ideia, aqueles que fazem uso da obstrução justificam-na considerando que os sujeitos não devem possuir um campo de escolhas que lhes assegure a liberdade de escolha, pois, caso os sujeitos a possuam, escolherão o que não é recomendável pela Razão, pelo Livro Religioso etc. Quando a lei estabelece um conteúdo substantivo a partir do qual os sujeitos serão livres, estamos falando de uma intervenção arbitrária. Nesse modelo, a lei estabelece o que os sujeitos devem desejar, e não um espaço no qual eles realizam suas escolhas. Tal tentação é, para o PV, uma ameaça presente não apenas nas doutrinas explicitamente autoritárias, mas um perigo que ronda o próprio liberalismo. Como exemplo dessa tentação, Berlin menciona Locke e Montesquieu, quando estes estabelecem que ser livre é agir de acordo com as leis, as quais conduzem os sujeitos a fins racionais ou em direção ao bem geral (Berlin, 2002a, p. 251). 
Nessa visão autoritária, “[...] forçar os eu empíricos a adaptarem-se aos padrões corretos não é tirania, mas libertação" (Berlin, 2002a, p. 251). A lei lida com os sujeitos não como seres plenos, mas como crianças, que devem ser educadas para então serem capazes de escolher, ou como sujeitos a serem moldados em direção a um fim superior: "A coação é também uma espécie de educação", frase de Fichte que ilustra, segundo Berlin, a ideia de paternalismo despótico. Quando a lei retira dos indivíduos sua escolha, fá-lo tendo em vista uma educação que os prepara para a verdadeira liberdade. Neste contexto, conclui Berlin, faz sentido a frase de Bentham: “[...] o propósito das leis não era libertar, mas restringir: toda lei é uma infração da liberdade" (Berlin, 2002a, p. 252). A lei torna-se um instrumento arbitrário quando lida com os sujeitos como seres inferiores, aos quais alguns bens que eles desejam devem ser negados. Portanto, no sentido discutido acima, e apenas neste 178 sentido, podemos considerar que o PV postula que a lei entendida como uma intervenção arbitrária - é uma infração da liberdade. Isso porque o que está sendo bloqueado é a presença perante o sujeito de diversos fins razoáveis e conflitantes, entre os quais é chamado a escolher.

A segunda modalidade de obstrução manifesta-se quando um conjunto de regras aparentemente impessoais gera um bloqueio no acesso a bens socialmente relevantes, seja esse resultado intencional ou não. Uma legislação que permita a concentração de recursos sociais em um grupo social, excluindo os demais, consiste em uma violação dos dois tipos de liberdade, positiva ou negativa. Dessa maneira, a obstrução da liberdade não se manifesta apenas quando uma intervenção arbitrária emerge, mas também quando se permite uma concentração de recursos sociais ou simbólicos em detrimento de um grupo. Sendo assim, uma legislação que não evite essa concentração é igualmente uma manifestação de uma obstrução. $\mathrm{O}$ fato de que tal bloqueio não 
seja nem aberto nem brutal não o torna menos arbitrário ao exercício da liberdade. (Berlin, 1984, p. 27). Empregando o termo utilizado neste artigo: é também uma obstrução.

A terceira modalidade ganha a forma de uma ameaça, a qual, para ser eficaz, pode manifestar-se apenas por meio de um sinal, provocando no agente um receio de violar a vontade do outro sujeito. A partir dessa ameaça o sujeito adequa suas preferências aos desejos daquele que concentra os meios necessários para atingir um determinado fim. $\mathrm{O}$ fato de que não tenha ocorrido uma intervenção arbitrária explícita não impede que seja considerada uma obstrução (Berlin, 2002a, p. 234).

O conteúdo comum dessas três manifestações consiste no seguinte: existem certos fins almejados por um grupo ou por um sujeito, mas que não estão disponíveis ou não podem ser usufruídos por nenhum motivo que não seja a vontade arbitrária de um grupo em preservar tais bens para si ou para seus eleitos. A obstrução pode ser explícita ou pode ganhar contorno impessoal, pode consistir na permissividade para com uma situação de concentração de recursos que impede o acesso a um bem; a obstrução pode manifestar-se como uma ameaça, não necessariamente explícita, mas como sugestão velada.

\section{A lei como não interferência}

No segundo sentido de lei, esta é entendida como uma intervenção que estabelece os limites dentro dos quais o sujeito pode buscar os fins que considera desejáveis. A lei seria definida pelo seu caráter negativo - e, por esse termo, entenda-se que a lei, ao invés de prescrever determinados conteúdos para a ação, estabelece e protege os domínios legítimos a partir dos quais o indivíduo é livre para agir. A lei remete à ideia de direito mencionada anteriormente: cabe ao sujeito fazer ou não determinada ação, não há o sentido de um dever, não cabe à lei estabelecer o que deve 
ser feito. O Estado cuida principalmente de que o sujeito não seja forçado a agir em determinada direção, que acordos sejam respeitados, e protege os bens e a pessoa dos cidadãos. Quando Berlin (2002a, p. 233-234; 2009b, p. 217) discute essa concepção, ele designa-a como a função do vigia, cuja única finalidade é impedir o abuso e puni-lo quando ocorrer.

Esse entendimento da lei como não intervenção acarretou a interpretação de que o PV possuiria uma afinidade teórica com o libertarismo (Vita, 2011, p. 571). E é importante observar que o PV não recusa a ideia da lei como um instrumento por meio do qual o sujeito recebe segurança contra violações à sua privacidade, da mesma maneira que reconhece o papel da propriedade individual como um meio para a liberdade. Isso não implica, todavia, que o PV considere a lei como não interferência, como a única modalidade de lei desejável.

Na perspectiva pluralista, o libertarismo está assentado em um postulado monista de lei que, caso adotado, produz graves distorções para o arranjo político pluralista. A lei como não interferência, conforme entendida pelo libertarismo, privilegia dois valores: segurança e dinheiro. Em um mercado espontâneo, o dinheiro torna-se o valor dominante, o que o conduz a tornar-se o meio pelo qual os sujeitos medem sua satisfação ou insatisfação (Hayek, 1981, p. 51). Ocorre que qualquer esfera que seja guiada por um único valor não corresponde à diversidade de fins razoáveis existentes em uma sociedade plural. Estabelecer que o mercado livre venha a ser sempre o melhor juiz na distribuição fere uma ideia-chave do pluralismo, qual seja, na medida em que não existe um fim único na sociedade, é desejável que por meio do debate político transcorrido na sociedade civil se manifestem diversos fins. No debate político emergirão diversos fins produzidos por esferas sociais regidas por fins e valores distintos daqueles presentes no mercado. 
Como escreveu Berlin em DCL, em certas circunstâncias uma sociedade pode considerar que as desigualdades sociais chegaram a um ponto em que ferem noções básicas de solidariedade social e deliberar pela necessidade de medidas que, restringindo a liberdade individual presente no mercado, venham a introduzir maior igualdade social. Para aqueles que tomam a liberdade individual como um valor intocável, essa negociação será impossível, mas tal visão é, no enfoque pluralista, uma distorção. Tal movimento é produzido pela ideia de que a sociedade deve ser regida por um único fim (Berlin, 2002a, p. 232).

Na ótica pluralista, o libertarismo distorce a liberdade negativa, surgindo da conjunção entre uma determinada compreensão da liberdade negativa com um arranjo político-social marcado pelo laissez-faire incondicional. A crença na liberdade negativa como a única métrica nas relações sociais produziu um arranjo político-social que passou a considerar que toda forma de intervenção, com vistas a garantir outros fins que não fossem a proteção do indivíduo tomado isoladamente, deveria ser considerada contrária à liberdade.

A perspectiva de um único valor que forneça a métrica moral para uma sociedade constitui-se no enfoque do monismo, o qual reduz a diversidade de fins existentes a um único fim. Tal procedimento pode afetar qualquer sistema de valores, inclusive um sistema liberal. Como escreveu Berlin (1981, p. 26): "Cada conceito pode se tornar uma perversão para a qual ele foi criado para resistir".

Essa perversão pode ocorrer sempre que os elementos de diversidade, de conflito e de escolha entre os fins forem suprimidos em favor da ideia de que um único fim é capaz de fornecer a métrica para as leis. Na ótica pluralista, a finalidade da lei como uma intervenção deliberada consiste em fornecer as bases para a diversidade de fins existentes na sociedade. A liberdade negativa é uma das esferas na 
qual esses elementos se manifestam. Aqueles que centram sua análise na proximidade entre libertarismo e PV não percebem que a ideia-chave deste não está na liberdade negativa, mas na diversidade de fins. $\mathrm{O}$ foco exclusivo nos valores correspondentes da liberdade negativa gera uma perversão característica do monismo. A liberdade negativa possui enorme pertinência enquanto acolhe as ideias de diversidade, conflito e liberdade de escolha, mas, quando se torna a única finalidade em uma sociedade, ocorre a distorção assinalada anteriormente: a liberdade negativa destrói o próprio exercício da liberdade de escolha entre fins diversos e conflituosos. A essa distorção teórica correspondeu um problema no plano das consequências provocadas por essa concepção de lei.

Na concepção de lei como não intervenção, a sociedade deveria ser guiada por uma disputa pacífica cujo resultado final seria sempre favorável à liberdade. Na "Introdução", 182 Berlin (1981, p. 25) alerta que essa crença é compatível com a criação de grandes e duradouros males sociais, os quais foram, principalmente, a concentração de recursos nas mãos de poucos:

A defesa da não interferência (como o darwinismo social) foi claramente usada para dar apoio às políticas socialmente destrutivas que armavam os fortes, os violentos e os inescrupulosos contra os benevolentes, os menos afortunados. [...] Liberdade para os lobos quase sempre significa morte para os cordeiros. (Berlin, 1981, p. 25)

O resultado da lei como não interferência foi destruir qualquer espaço para a autonomia do sujeito e para a manifestação da diversidade de fins. A compreensão da lei como não interferência destruiu tanto a esfera da liberdade negativa quanto da liberdade positiva. A liberdade 
negativa fornece muros que protegem o sujeito. Muros que, dentre outros meios, permitem aos sujeitos exercer sua autonomia na esfera pública. A liberdade de associação, por exemplo, que protege os sujeitos com interesses iguais e permite-lhes agir publicamente em nome desses interesses, foi destruída pela ideia de lei como não interferência (Berlin, 1984, p. 25). A lei como não interferência corresponde, no PV, ao que Berlin descreve como sendo uma operação defensiva (Berlin, 2009b, p. 222). Ela é fundamental, mas não traz o fim que o sujeito pretende realizar ao executar a sua ação. Nesse sentido ela é defensiva porque defende valores intrinsecamente importantes para o sujeito - amor, amizade, justiça etc. - mas é necessário que existam fins a serem preservados (Berlin, 2009b, p. 222). E não é ela quem produz esses fins, nem serve como métrica para sua gestação.

Para o PV, a lei como não interferência não possui uma carga negativa enquanto é pensada e combinada com outras concepções de lei orientadas por valores distintos e, principalmente, enquanto contribui para a autonomia do sujeito e para a manifestação da diversidade. Se a lei como não interferência protege o sujeito oferecendo-lhe o direito, a faculdade de fazer ou não fazer, de praticar ou não praticar determinada ação, estamos em uma esfera aceitável. O problema nasce quando ela se torna a única concepção de lei moralmente aceitável.

Pluralismo e liberalismo não são conceitos idênticos, pois existem teorias liberais que não são pluralistas. A passagem de uma teoria liberal para o campo pluralista precisa necessariamente reconhecer que não é possível estabelecer um critério único para as questões morais, devendo-se assegurar que na sociedade se manifestem valores distintos e conflitivos (Berlin e Williams, 1994, p. 308; Berlin e Jahanbegloo, 1996, p. 72-73). O libertarismo, quando toma o sujeito isoladamente e o mercado como 
padrão a partir do qual são julgados todos os fins, perde o elemento pluralista. ${ }^{3}$

\section{A lei como uma intervenção moralmente aceita}

O ponto de partida para pensar a lei como uma intervenção moralmente aceita no PV consiste em considerar a ideia de diversidade de fins como um conteúdo não substantivo. A ideia de diversidade abarca o seguinte conteúdo: na experiência ordinária de homens e mulheres estão presentes fins diversos - justiça, segurança, bem-estar material, fraternidade etc. - e que são razoáveis para o florescimento humano. Como cada fim representa um fim em si mesmo, eles não podem ser reduzidos a uma única métrica. Em certas circunstâncias, esses fins últimos entram em conflito. Na medida em que correspondem a dimensões distintas do florescimento humano, não podem ser suprimidos sem prejuízos à condição humana. Nem todos os fins podem ser atingidos 184 ao mesmo tempo nem existem recursos para a efetivação de todos. Torna-se necessário realizar escolhas trágicas entre eles. De maneira a que a escolha não seja fundada no relativismo moral, Berlin aponta a necessidade de que sejam estabelecidos compromissos práticos com vistas a atingir certos fins, o que implica considerar que certas reivindicações

\footnotetext{
3 Em carta a Bernard Crick, Berlin manifesta seu descontentamento com as posturas monistas de Hayek e seus seguidores. O conteúdo desta está presente na "Introdução" publicada em 1969: "Minha principal dificuldade é simplesmente que eu concordo com você mais do que (você) concorda comigo: não apenas contra o óbvio inimigo comum (os supressores das diferenças em favor de uma solução final), mas contra os fanáticos individualistas - anti-planejadores, laissez-fairistas, hayeanos e até proudhonistas (que odeiam o Estado, e acreditam na sacralidade da pequena propriedade como uma garantia de moralidade), e assim por diante; e isso, não apenas porque tais pessoas elevam a não-interferência em um objetivo supremo, e desconsideram as reivindicações de segurança, justiça, igualdade e simples humanidade, como os verdadeiros libertinos do século XIX, [...] que vêem monstros totalitários na mais suave, na mais desesperadamente necessária reforma social, New Deal e socialista; mas também porque essas pessoas não percebem que algumas liberdades ameaçam outras liberdades; e como você diz, algumas liberdades perecem sem planejamento social" (29 de março de 1966: L3 271). Disponível em: http://berlin.wolf.ox.ac.uk. Acesso em: 6 ago. 2019.
} 
devem ceder em nome de uma solução prática, ocorrendo assim uma escolha que representa uma hierarquia entre fins (Berlin, 2002a, p. 232; Berlin, 2002b, p. 49-51). Nessa operação, dois aspectos são importantes. Em primeiro lugar, alguns fins ganham precedência em decorrência de um debate público que conduz esse ordenamento. Em segundo lugar, a lógica que guia essa hierarquia não é estabelecida por um algoritmo, mas por uma razão prática que leva em consideração diversos fins distintos e conflitivos, que não podem nem devem ser reduzidos a uma medida comum (Berlin e Willians, 1994, p. 307).

Crowder $(2002 ; 2018)$ propôs uma articulação conceitual entre a ideia de compromisso prático, postulada por Berlin, com o conceito de phronesis, proveniente de Aristóteles. Na teoria aristotélica, a phronesis representa a ideia de que a deliberação ocorre em contextos particulares que não estão sujeitos a uma regra universal e que, dessa maneira, são passíveis de intervenção humana. Na medida em que os contextos particulares são variáveis, tal fato requer do observador uma atenção à diversidade dos elementos que moldam cada contexto específico (Aristóteles, 1984, Livro VI, 7, 1141b8-145).

Nesse sentido, aponta Crowder, a ideia de compromisso prático reconhece a existência de diversos fins necessários para o florescimento humano, mas fá-lo tendo em vista um contexto particular, a partir do qual deverão ser escolhidos certos fins em detrimento de outros. Esse compromisso prático será o produto de um debate público, durante o qual ocorrerão lutas, dissensos, acordos etc., por meio dos quais emergirá um pacto temporário. Será fundamentalmente um processo político. Está presente nessa ideia uma valorização da ação política entendida com uma razão contingencial, capaz de engendrar acordos e enfrentar dilemas. Esse processo resulta em um compromisso temporário, cujo resultado final estabelece uma hierarquia, mas na qual está 
reconhecido o valor da diversidade e da possibilidade de que outros ordenamentos seriam possíveis.

Essa discussão é retomada por Galston (2002), que reflete sobre uma concepção de lei aceitável em termos do PV. Nessa tarefa, Galston recepciona o argumento de Perelman (2004) acerca da lei, que, por sua vez, possui pontos de contato fortes com o PV. Segundo o autor francês, o direito move-se em um contexto marcado pela diversidade e pelo conflito entre fins igualmente razoáveis. A partir desse entendimento, ele efetua uma releitura de Aristóteles que recupera o papel da retórica e da lógica dialética como recursos válidos para a esfera do direito.

Em Aristóteles, a dialética consiste em um método em que, partindo de opiniões correntes, são produzidos silogismos. A partir do desenvolvimento de uma argumentação a favor e contra uma opinião, revela-se o verdadeiro caráter desta. A retórica utiliza-se dos mesmos recursos da dialética, pois ambas partem de premissas verossímeis como base para a produção da convicção. As duas recorrem à endoxa, ou seja, às opiniões sustentadas por um número elevado de pessoas ou por um pequeno número de especialistas, como um ponto de partida. Tal ponto de partida não é aleatório, pois nele manifesta-se a phronesis (Aristóteles, 1984). A lógica dialética e a retórica fazem uso das premissas de maneira distinta daquela presente na lógica formal, sem que elas percam sua relevância na discussão dos assuntos sujeitos à deliberação humana.

Partindo dessa ideia geral, Perelman aponta que a lógica jurídica, como a dialética em Aristóteles, não parte de premissas verdadeiras e primárias, mas de opiniões que são aceitas pela maioria (Perelman, 2004, p. 153). A partir do debate entre elas chega-se a uma decisão que, frente a outras decisões possíveis, foi entendida como a mais razoável naquele contexto específico. Nessa decisão final não é negada a possibilidade de que, em razão de um outro contexto, não 
fosse possível uma outra deliberação. Esse reconhecimento implica conceitualmente distinguir entre um discurso sobre o real e um discurso sobre os valores. No discurso sobre o real o que se opõe ao verdadeiro é o falso. O que é verdadeiro para alguns, deverá sê-lo para todos. Nesse argumento, não há espaço para a escolha entre fins diversos e razoáveis. $\mathrm{Na}$ perspectiva apresentada por Perelman, o que se opõe a um valor não deixa de ser um valor, a despeito da importância que o sujeito concede ao valor escolhido. Em outras palavras, a despeito de realizar uma escolha, o sujeito reconhece relevância no valor preterido, assim como reconhece que em outras circunstâncias ou por uma mudança nos fins desejados esse valor possa ser adotado (Perelman, 2004).

Nesse sentido, o conceito de compromisso prático proposto pelo PV compreende a ideia de lei. Esta representa o esforço de sujeitos razoáveis movidos por concepções diversas de bem em chegar a um acordo, sem que em nenhum momento as diferenças sejam suprimidas. A deliberação nessa esfera afasta-se tanto do decisionismo como do determinismo, consistindo no esforço em escolher o melhor curso tendo em vista as circunstâncias e a diversidade de fins envolvidos (Galston, 2002, p. 69-70). A lei deixa de expressar a verdade única, a qual seria construída a partir de premissas indiscutivelmente verdadeiras, que resultam, em razão de inferências válidas, em conclusões igualmente necessárias. Nesta concepção, a lei passa a ser entendida como o resultado de um debate político no qual concorrem diversas concepções de bem, sem que esse debate se oriente por um princípio comum a todas. Tal ideia não implica a perspectiva de que qualquer ordenamento de leis seja aceitável; permanece o reconhecimento da diversidade de fins distintos e conflitivos como um princípio norteador (Berlin e Willians, 1994, p. 307). Na ótica pluralista, o reconhecimento de que o bem é plural implica considerar que entre as diversas concepções de bem estão presentes 
conflitos para os quais não existe uma solução certa. Isso não significa dizer que não exista uma solução adequada para aquele contexto, mas que existem muitas soluções possíveis (Gray, 2000a).

Na medida em que o PV concebe a possibilidade de formular uma lei que intervenha a partir de uma hierarquia de fins estabelecida a partir de uma razão prática, impõe-se indagar como essa perspectiva enfrenta um dos seus postulados centrais: a incomensurabilidade entre os fins.

\section{A lei como um ordenamento entre fins incomensuráveis}

A discussão teórica acerca do papel da lei no PV envolve analisar como uma teoria que opera a partir da ideia de que os fins são incomensuráveis pode refletir sobre a lei como um ordenamento. Em que medida essa teoria, ao afirmar o papel da lei como uma intervenção moralmente aceitável, não contradiz seu postulado teórico de que não é possível 188 nem desejável suprimir essa diversidade conflituosa? De acordo com Dworkin, a maneira pela qual Berlin estabeleceu a incomensurabilidade de fins acarretou uma escolha entre valores absolutos que não permitiria acordos: toda escolha representaria uma perda (Dworkin, 2010, p. 158-162). Dessa maneira, toda intervenção pública representaria uma perda, aspecto que, levado à suas últimas consequências, implicaria legar milhões de pessoas à miséria permanente (Dworkin, 2001, p. 75).

Dentro do PV apresentam-se dois enfoques acerca da ideia de incomensurabilidade. Ambos estão presentes na obra de Berlin, sem que este tenha fornecido uma resposta estável ao problema. Os dois enfoques geraram caminhos teóricos distintos. $\mathrm{O}$ primeiro estaria centrado na ideia de que toda escolha entre fins é, em última instância, contingente e arbitrária, sendo John Gray (2000a; 2000b) o autor que desenvolve essa ideia. O segundo enfoque, desenvolvido por George Crowder e Willian Galston, postula a diversidade 
de fins como um metavalor que expressa a noção de respeito pelos fins humanos genuínos. $\mathrm{O}$ fato de o PV operar a partir da ideia de incomensurabilidade não o impede de estabelecer uma hierarquia entre os fins e, portanto, pensar sobre uma intervenção moralmente aceitável. Essa intervenção representa um ordenamento em torno de um conjunto coerente de valores, calcado nos valores da autonomia do sujeito e da diversidade de fins.

O primeiro entendimento sustenta que, se os fins são incomparáveis, não é possível estabelecer nenhum critério razoável de escolha; a decisão referir-se-á a valores últimos, os quais são justificáveis a partir do seu conteúdo. Mas não existe nenhuma comparação razoável entre os fins; quando os fins colidem, ser racional é escolher a conduta na qual o sujeito acredita (Berlin, 1981, p. 31). Nessa perspectiva, quando o sujeito escolhe, sempre ocorre uma perda absoluta para com outros fins. Cada fim é um conjunto de valores que fecha o sujeito em torno deles, bloqueando qualquer comparação ou um acordo. Sendo assim, não é possível formular uma prioridade que represente um compromisso que estabeleça perdas em algumas esferas enquanto em outras o fim almejado seria preservado. Essa compreensão está presente em alguns trechos de DCL. É exemplar dessa perspectiva a maneira pela qual é abordado o conflito entre liberdade e igualdade. Berlin estabelece o seguinte: "se o sujeito consente em perder sua liberdade individual em favor de uma maior justiça social, a despeito da virtude do ato, isto não oculta que houve uma perda absoluta de liberdade" (Berlin, 2002a, p. 232).

Crowder aponta que há outro entendimento dentro da própria obra de Berlin. Este alertou para o fato de que em certas situações, frente a colisões entre fins, deve-se buscar trocas compensatórias nas quais alguns valores cedem frente a outros, tendo em vista a necessidade de preservar uma paz interna (Berlin, 2002b, p. 55-56). Como essas trocas 
devem ocorrer ou qual o conteúdo do pacto é algo que tomará como base as circunstâncias - "a situação concreta é quase tudo" (Berlin, 2002b, p. 56). Considerar o contexto não exclui estabelecer alguns valores que possuem centralidade para o PV: diversidade de fins e autonomia. Como eles serão pesados e quais valores e fins aos quais eles estarão associados não é uma tarefa passível de ser estabelecida a partir de um algoritmo (Berlin e Willians, 1994, p. 308), mas de uma razão prática que estabelece uma classificação entre os diversos fins. Estabelecer um ordenamento torna-se um problema na ótica pluralista ao postular-se uma medida abstrata que pretenda suprimir a diversidade. Se os fins são incomensuráveis, não há motivo para ordená-los sempre da mesma maneira em todos os contextos (Crowder, 2018).

A partir dessa perspectiva, a reflexão teórica do PV retoma a disjuntiva conceitual entre liberdade e igualdade. 190 Ambos são fins distintos, de tal maneira que não podem ser reduzidos um ao outro nem sintetizados em torno de um valor supremo como, por exemplo, a utilidade. Mas isso não exclui a possibilidade de que, em certos contextos, possa haver motivos que justifiquem a concessão de uma prioridade para a igualdade, tampouco que não possam ser realizados acordos que preservem certas áreas mais afeitas à liberdade enquanto em outras predomine a igualdade (Crowder, 2010). Nesse sentido, a discussão empreendida por Berlin na "Introdução" a DCL é um exemplo da aplicação dessa lógica.

Uma parte substantiva das críticas ao pluralismo consistiu em apontar sua propensão a permitir arranjos favoráveis à liberdade individual em detrimento da igualdade social. De acordo com essa crítica, o pluralismo afirmava a diversidade e a incomensurabilidade de fins, mas terminava estabelecendo uma precedência para a preservação de uma esfera protegida para o sujeito tomado na sua individualidade, fato 
que terminava bloqueando formas de intervenção que visassem a introduzir maior igualdade social. ${ }^{4}$

Na ótica pluralista é possível formular de maneira positiva modalidades de intervenções públicas que afetem a liberdade negativa, desde que ancoradas em um debate público e com vistas à diversidade de fins e à liberdade de escolha.

Pensar a lei como um conjunto de direitos válidos apenas no plano formal é de pouca valia para uma abordagem pluralista. Mencionar o direito de ir e vir para sujeitos que não dispõem de bens materiais mínimos para a sobrevivência diária é uma ação desnecessária. Discorrer sobre a importância da leitura como um reforço da autonomia do sujeito para aqueles que não possuem o acesso à escola pode propiciar um discurso belo, porém inócuo (Berlin, 1981, p. 30).

Não há no PV espaço para uma distinção entre liberdade formal e liberdade real: a liberdade é sempre a liberdade de escolha entre várias alternativas. Essa liberdade diz respeito ao conjunto de portas que estão abertas para o sujeito. Para tanto, a escolha de uma dentre elas ou a prerrogativa de não escolher já são partes da ação livre. A distinção que existe é entre as condições para a liberdade e o seu conteúdo. O PV reconhece a relevância das condições que sustentam o exercício da liberdade, mas aquelas não se confundem com esta.

Sem condições efetivas para a prática da liberdade na forma de oportunidades para educação, emprego e reflexão crítica, o exercício da liberdade é um bem inócuo. Dessa maneira, quando distingue as condições para a liberdade e a sua prática, em nenhum momento o PV exclui a necessidade de políticas públicas que promovam certos bens socialmente relevantes. Berlin (1981, p. 30-31) menciona a obrigação de promover educação, justiça, saúde etc. Nesse sentido, não está discutindo se cabe ou não distribuir esses bens, mas,

${ }^{4}$ Como um exemplo deste argumento veja-se Macpherson (1973). 
ao contrário, está mencionando a imperiosa necessidade de que eles sejam distribuídos igualmente - e distribuídos preferencial, mas não exclusivamente, pelo Estado. A intervenção pública possui, nos termos de Galston (2002, p. 39), uma relativa prioridade no ordenamento e na promoção dos bens socialmente relevantes. Mas tal ação pode e, mais do que isso, deve ser compartilhada com outros grupos e instituições autônomas presentes na sociedade civil, de maneira que diversos valores e fins estejam presentes nesta ação.

A intervenção pública com o intuito de promover certos bens pode implicar um conflito com a liberdade individual. Entretanto, trata-se de sacrificar alguns fins em favor de outros, a despeito de resistências existentes na própria sociedade. A educação constitui-se em uma ferramenta poderosa para abolir distinções sociais arbitrárias decorrentes de fatores casuais como o nascimento. Mas Berlin (1981, p. 30) não é favorável apenas a uma educação ampla, mas também 192 a um sistema uniforme de ensino geral em nível primário e secundário, na medida em que isso reforçaria a igualdade social (Berlin, 1981, p. 30). ${ }^{5}$

Propiciar essa educação geraria diversas consequências, como um reforço da solidariedade social e uma preparação maior e mais eficaz de adultos para o mercado de trabalho. Essas consequências são importantes, mas também há um valor que se constitui em ponto central de uma intervenção pública sob a ótica pluralista: "A necessidade de prover oportunidades de livre escolha ao maior número de crianças, o que provavelmente crescerá com a igualdade de ensino" (Berlin, 1981, p. 30). Tal intervenção poderia acarretar

\footnotetext{
5 A meu ver, há uma ênfase excessiva na ideia de uniformidade. Um valor mais próximo ao pluralismo político invocaria a necessidade de que fosse reconhecida autonomia às unidades políticas subnacionais para adotar conteúdos adequados às suas realidades e a reconhecer grupos religiosos e étnicos a fazerem o mesmo. Galston (2002) efetua uma análise mais ponderada do tema da educação sob a ótica pluralista.
} 
resistências da parte de sujeitos que consideram a educação um direito pertencente à sua esfera da liberdade negativa.

A redução da área de não interferência pretendida pelos pais seria o resultado de uma ação que visa a propiciar condições igualitárias para todos, de maneira que todos possam desfrutar de uma educação que lhes permita exercer a liberdade de escolha entre diversos fins presentes na sociedade (Berlin, 1981, p. 30).

Ocorre uma perda da liberdade negativa, mas esta não é a métrica absoluta que rege todas as esferas da sociedade. Se a análise aponta que, com um sistema de educação uniforme para todos, aumentam as oportunidades de escolha do sujeito, reforça-se a sua capacidade crítica e desobstruem-se barreiras arbitrárias a certos bens, não há por que bloquear a intervenção em nome de outro fim igualmente incomensurável, no caso relacionado à liberdade negativa. Neste ponto deve ser assinalada a centralidade do tema da diversidade de fins e da liberdade de escolha como princípio que, prima facie, orienta a lei moralmente legítima sob a ótica do PV (Crowder, 2018). A prioridade conferida a esses valores não exclui a dimensão da escolha trágica nem a existência de outros fins que poderiam ter orientado o arranjo político. Mas, a despeito da colisão, a escolha deve ser feita, tendo como base as circunstâncias sociais e políticas, mas mirando a necessidade de criar condições para aqueles que não as possuem possam exercer a liberdade de escolha (Berlin, 1981, p. 30-31).

Portanto, torna-se claro que, perante resistências, é legítimo invocar a intervenção pública como uma forma de ação que visa a estabelecer certos fins. Neste caso: igualdade social, fim de barreiras arbitrárias e, fundamentalmente, liberdade de escolha a todos entre fins diversos e conflituosos. Na medida em que o PV empresta relevância a esse tipo de liberdade, não apenas uma educação igualitária é desejável, mas também outros meios são requisitados. 
No enfoque pluralista deve-se considerar em primeiro lugar a atenção às circunstâncias que moldam cada sociedade, o que implica recusar qualquer métrica calcada em um ponto arquimediano, seja ele o direito, o mercado ou a religião. Tal relevância decorre do fato de que o PV confere peso ao debate político que se desenrola em uma determinada conjuntura; é nele que são construídas alianças e adversários, o que torna toda política pública o resultado desses embates. Em segundo lugar, para o PV, o reconhecimento do contexto histórico-político em cada sociedade produz suas políticas públicas, mas isso não implica elidir certos pressupostos: a importância da diversidade, a acomodação entre divergências razoáveis, a promoção da autonomia individual e o reconhecimento da presença de diversos grupos autônomos na sociedade. Nesse sentido, o PV privilegia a ideia de que as políticas públicas devem enfatizar o fornecimento de capacidades para os sujeitos efetuarem 194 suas escolhas. ${ }^{6}$ A escolha do PV pelo ideal de capacidades é coerente com sua ideia norteadora: a diversidade e incomensurabilidade entre os fins. Cada capacidade representa um bem distinto e não redutível aos demais, e nenhuma dessas capacidades é intrinsecamente mais importante do que outra (Crowder, 2009, p. 795).

Entretanto, o quanto e como elas serão valiosas é uma questão que cabe ser decidida em face das desvantagens sociais a serem combatidas e de que fins devem ser promovidos. As políticas públicas fornecem a base a partir da qual os sujeitos empreendem as suas escolhas, algumas delas excludentes em relação a outras escolhas. Em que medida, por exemplo, o sujeito conferirá precedência a sua carreira profissional ou à família é uma questão que pode implicar escolhas entre dois fins que em certas circunstâncias

\footnotetext{
${ }^{6}$ Nussbaum (2000, p. 78-80) enumera, em lista que não se pretende exaustiva, os seguintes âmbitos: saúde, corpo, integridade, sentidos, imaginação e pensamento, emoções, razão prática e filiação, dentre outros.
} 
podem colidir, cabendo ao sujeito deliberar entre eles (Crowder, 2009, p. 796-797).

A discussão antecedente fornece uma base para a análise da crítica neorrepublicana ao PV. De acordo com essa crítica, Berlin teria defendido uma teoria da liberdade como não intervenção. A teoria política neorrepublicana possui diversos elementos relevantes que contribuíram para o debate político contemporâneo. Entretanto, suas críticas ao pluralismo de valores possuem alguns aspectos que merecem uma análise mais detida.

Em primeiro lugar, merece atenção o fato de que seu foco recai exclusivamente sobre o conceito de liberdade negativa (Pettit, 2011). Tal centralidade implica inevitavelmente deixar intocada a ideia central do PV: a diversidade e o conflito entre fins e a liberdade de escolha. Tal postulado implica ignorar que o motivo pelo qual Berlin conferia relevância à liberdade negativa decorria do seu acolhimento desses valores (Berlin, 2002a, p. 272).

A liberdade negativa possui enorme pertinência enquanto acolhe as ideias de diversidade, conflito e liberdade de escolha, mas, quando ela se torna a única finalidade em uma sociedade, ocorre a distorção assinalada anteriormente: a liberdade negativa destrói o próprio exercício da liberdade de escolha. Distorções são plenamente realizáveis por ambas as concepções de liberdade, tanto a positiva quanto a negativa. Essa perversão pode ocorrer sempre que os elementos de diversidade, de conflito e de escolha entre os fins forem suprimidos em favor da ideia de um único fim capaz de fornecer a métrica para as leis. Na ótica pluralista, a finalidade da lei como uma intervenção deliberada consiste em fornecer as bases para a diversidade de fins existentes na sociedade. A liberdade negativa é uma das esferas na qual esses elementos se manifestam.

Em segundo lugar, Berlin define a liberdade negativa como "a área em que um sujeito - uma pessoa ou um 
grupo de pessoas - tem ou deve ter permissão para fazer ou ser o que é, sem a interferência de outras pessoas" (Berlin, 2002a, p. 229). Dessa definição, segue-se, para o neorepublicanismo, a ideia de que o PV recusaria qualquer forma de intervenção.

Em relação a essa ideia, dois aspectos são importantes. Em primeiro lugar, a discussão precedente mostra que nem toda intervenção é contrária ao exercício da liberdade do sujeito ou do grupo ao qual ele pertence. A lei pode possuir valores que contribuem ou reforçam o sujeito no exercício da sua autonomia enquanto sujeito que se encontra perante fins diversos e conflitantes.

Em segundo lugar, essa ideia pode ser complementada em uma análise da própria definição de liberdade negativa na sua integralidade. Atendo-se ao argumento de Berlin, conforme discutido anteriormente, é fundamental assinalar que ser obstruído significa uma intervenção arbitrária.

Se não é entendida a diferença entre obstrução e intervenção perde-se um elemento constitutivo e decisivo para o entendimento do conceito. Se eu pretendo alcançar um objeto e outro sujeito interpõe-se e impede-me de alcançá-lo, sem motivos justos - porque ainda não estou pronto para usufruir da minha liberdade, porque tal bem não seria adequado para mim, porque não sou racional o bastante para fazer uso desse objeto etc., ou seja, tudo aquilo que Berlin designa como concepção paternalista -, é correto mencionar que essa ação é uma obstrução e que a liberdade consiste em uma área desimpedida de tais "intervenções". Mas se pretendo alcançar um objeto, e um sujeito ou uma instituição intervêm de maneira a fornecer-me meios que me auxiliem na obtenção desse bem - como, no exemplo discutido anteriormente, educação -, a intervenção não afeta a minha área desobstruída. Nesse sentido, a própria esfera da liberdade negativa não prescinde de elementos que forneçam sustentação para a ação dos sujeitos. Nessa 
lógica, Berlin aponta a importância dos direitos sociais implementados pelo Estado de bem-estar social:

Os apelos em favor do planejamento, do Estado de bemestar social e do socialismo podem ser construídos, com a mesma validade, a partir da consideração pelas demandas em favor da liberdade negativa, como o são da sua irmã, a liberdade positiva. (Berlin, 1981, p. 26)

Se, como pretendem os neorrepublicanos, entendemos a liberdade negativa como uma área que se define antes pela não intervenção, o trecho acima seria contraditório. Mas o problema só existe porque foi entendido que a ausência de qualquer tipo de intervenção seria necessária para definir a esfera da liberdade negativa. Conforme observamos anteriormente, Berlin define a liberdade negativa como uma área desobstruída. Nem Berlin nem nenhum dos pluralistas aqui discutidos jamais estabeleceu que a liberdade negativa não requeresse modalidades de intervenção que lhe dessem sustentação. A partir de uma razão prática é possível formular, entre os objetivos dessa intervenção, direitos sociais como educação, saúde, segurança, privacidade etc. ${ }^{7}$

É razoável a pergunta: como fica a definição que estabeleceu que a liberdade negativa consistiria em uma área na qual o sujeito não é restringido, coagido por outros?

\footnotetext{
${ }^{7}$ Segundo Silva (2011, p. 38): "Enquanto pensadores liberais como Isaiah Berlin estabelecem a necessidade da ausência de qualquer tipo de interferência intencional de terceiros como o critério da liberdade individual, Pettit destaca que não é qualquer forma de interferência intencional que se revela incompatível com a liberdade republicana, mas exclusivamente aquelas formas de interferência que podem ser qualificadas como arbitrárias". Conforme analisado anteriormente, a ideia de interferência é moralmente aceitável para o PV; o problema se apresenta quando a intervenção se torna uma obstrução e visa constranger, coagir etc. o sujeito nas suas escolhas. Toda intervenção que visa dar suporte à autonomia do sujeito perante a escolha entre fins razoáveis e diversos é perfeitamente aceitável para o PV. O mesmo equívoco pode ser encontrado quando o autor afirma que para o pluralismo a liberdade negativa define-se antes pela ausência do que pela presença (Silva, 2015, p. 197).
} 
Parte da resposta já foi dada anteriormente: uma área na qual eu posso agir sem sofrer uma obstrução arbitrária mas também é necessário pensar que essa área não existe sem condições que permitam a sua existência. Em nome dessa área o sujeito pode demandar bens que requeiram uma intervenção pública. Note-se e destaque-se que Berlin não está mencionando segurança e proteção legal como o libertarismo faz, mas direitos sociais. As condições sociais que permitem ao sujeito realizar suas escolhas são fundamentais para o próprio usufruto dos bens presentes na sua esfera protegida, mas não são a própria escolha nem o próprio processo a partir do qual ela ocorre.

A partir da discussão precedente pode-se avaliar a seguinte crítica: o PV tomaria a inviolabilidade da liberdade individual privada como valor absoluto; qualquer política distributiva somente poderia ser implementada se aceita voluntariamente pelos afetados por ela; caso contrário, 198 não poderia ocorrer qualquer política pública que visasse a maior justiça social. ${ }^{8}$

A resposta a tal crítica dar-se-ia da seguinte maneira: em primeiro lugar, a liberdade negativa, entendida como proteção ao indivíduo e ao mercado, não pode ser a métrica absoluta de todas as relações sociais, tampouco da produção das leis. Essa concepção produziu resultados contrários à liberdade de escolha entre diversos fins. Sob a ótica do PV, o libertarismo privilegia uma esfera social, o mercado livre e seu valor, em detrimento das demais esferas e seus valores, aspecto que entra em choque com o PV. Em segundo lugar, certas políticas públicas podem reduzir a esfera da liberdade

\footnotetext{
${ }^{8}$ Veja-se Miguel (2015, p. 33): "Berlin confere primazia lexicográfica à liberdade negativa. Com isto, o autogoverno - a esfera da igualdade de direitos - fica limitada pela intocabilidade da autonomia individual privada, isto é, da esfera em que o exercício da liberdade é condicionado pelos recursos diferenciados disponíveis para os indivíduos. Em particular, qualquer política redistributiva torna-se dependente da aceitação voluntária por parte dos controladores de riqueza, já que uma transferência compulsória para os mais pobres implica coerção externa”.
} 
individual em favor de medidas que produzam uma autonomia maior dos sujeitos. Tais medidas devem ser implementadas, a despeito das resistências encontradas. Em nenhum momento o PV estabelece que a liberdade individual seja uma medida absoluta.

Aqueles que tomam a liberdade individual como uma medida intocável perdem de vista que uma das finalidades desta esfera desobstruída é permitir que os sujeitos exerçam sua liberdade de escolha entre fins distintos e conflitivos. A crítica precedente reflete a perspectiva de que o PV e o libertarismo compartilhariam valores, principalmente a não intervenção e a liberdade individual. Na discussão empreendida, é possível identificar que a liberdade individual não possui esta primazia. $\mathrm{O}$ conceito que possui essa primazia é a ideia de pluralidade de fins, e uma política social não requer que os afetados por esta consintam pacificamente. $\mathrm{O}$ exemplo presente na discussão precedente permitiu apontar que os pais que dispõem de recursos para sustentar uma educação deverão ceder, mesmo que não concordem. No argumento do PV as prioridades e a lógica interna dos conceitos são distintas daquelas presentes no libertarismo, o que não implica estabelecer que a liberdade negativa não tenha relevância: em certas circunstâncias, ela pode ser preterida, mas não suprimida, em favor de outros meios e fins que promovam a liberdade de escolha entre fins distintos.

\section{Ivo Coser}

É mestre e doutor em ciência política pelo antigo Instituto Universitário de Pesquisas do Rio de Janeiro (Iuperj) e professor associado do Departamento de Ciência Política e do Programa de Pós-Graduação em História Comparada da Universidade Federal do Rio de Janeiro (UFRJ). Coordenador do Núcleo de Estudos em Teoria Política (Nutep) da UFRJ. Pesquisa sobre teoria política contemporânea. 


\section{Bibliografia}

ARISTÓTELES. 1984. Ética a Nicômaco. São Paulo: Abril Cultural.

BERLIN, Isaiah. 1984. Introdução. In: BERLIN, Isaiah. Quatro ensaios sobre a liberdade. Brasília: UnB, pp. 1-41.

BERLIN, Isaiah. 2002a. Dois conceitos de liberdade. In: HARDY, Henry;

HAUSHEER, Roger (org.). Estudos sobre a humanidade. São Paulo:

Companhia das Letras, pp. 226-272.

BERLIN, Isaiah. 2002b. A busca do ideal. In: HARDY, Henry; HAUSHEER,

Roger (org.). Estudos sobre a humanidade. São Paulo: Companhia das Letras, pp. 41-57.

BERLIN, Isaiah. 2002c. Ainda existe a teoria política? In: HARDY, Henry;

HAUSHEER, Roger (org.). Estudos sobre a humanidade. São Paulo:

Companhia das Letras, pp. 99-130.

BERLIN, Isaiah. 2002d. A originalidade de Maquiavel. In: HARDY, Henry;

HAUSHEER, Roger (org.). Estudos sobre a humanidade. São Paulo:

Companhia das Letras, pp. 299-349.

BERLIN, Isaiah. 2002e. Do medo e da esperança libertados. In: HARDY,

Henry; HAUSHEER, Roger (org.). Estudos sobre a humanidade. São

Paulo: Companhia das Letras, pp. 131-158.

BERLIN, Isaiah. 2005. Meu caminho intelectual. In: HARDY, Henry

(org.). A força das ideias. São Paulo: Companhia das Letras, pp. 17-46.

BERLIN, Isaiah. 2009a. A ideia de liberdade. In: HARDY, Henry (org.). Ideias políticas na era romântica. São Paulo: Companhia das Letras, pp. 149-215.

BERLIN, Isaiah. 2009b. Dois conceitos de liberdade: o romântico e o liberal. In: HARDY, Henry (org.). Ideias politicas na era romântica. São Paulo: Companhia das Letras, pp. 216-269.

BERLIN, Isaiah; JAHANBEGLOO, Ramin. 1996. Isaiah Berlin: com toda a liberdade. São Paulo: Perspectiva.

BERLIN, Isaiah; WILLIAMS, Bernard. 1994. Pluralism and liberalism: a reply. Political Studies, n. 41, pp. 306-9.

BUARQUE DE HOLANDA, Aurélio (ed.). 1999. Novo Aurélio século XXI. Rio de Janeiro: Nova Fronteira.

CALDAS AULETE (ed.). 1958. Dicionário contemporâneo da língua portuguesa. 4. ed. Rio de Janeiro: Delta.

COSER, Ivo. 2014. The concept of liberty: the polemic between the neorepublicans and Isaiah Berlin. Brazilian Political Science Review, v. 8, pp. 39-65.

CROWDER, George. 2002. Liberalism and value pluralism. New York: Continuum. 
CROWDER, George. 2004. Isaiah Berlin: liberty and pluralism. New York: Polity Press.

CROWDER, George. 2009. Pluralism, liberalism and distributive justice. San Diego Law Review, v. 46, n. 4, pp. 773-802.

CROWDER, George. 2010. Isaiah Berlin, pluralismo y liberalismo. In: BERLIN, Isaiah et al. Isaiah Berlin: utopia, tragédia y pluralismo. Medellín: Fondo Editorial Universidad, pp. 85-138.

CROWDER, George. 2013. In defense of Berlin: a reply to James Tully. In: Baum, Bruce; Nichols, Robert (ed.). Isaiah Berlin and the politics of freedom: "two concepts of liberty" 50 years later. London: Routledge, pp. 52-72. CROWDER, George. 2016. After Berlin: the literature since 2002. The Isaiah Berlin Virtual Library, Oxford. Disponível em: http:/ / berlin.wolf. ox.ac.uk/lists/onib/after-berlin.pdf. Acesso em: 8 out. 2018.

CROWDER, George. 2018. Pluralism, relativism, and liberalism. In: CHERMISS, Joshua L.; SMITH, Steven B. (ed.). The Cambridge companion to Isaiah Berlin. Cambridge: Cambridge University Press, pp. 229-249.

DWORKIN, Ronald. 2001. Do liberal values conflict? In: LILLA, Mark; DWORKIN, Ronald; SILVERS, Robert B. (ed.). The legacy of Isaiah Berlin. New York: New York Review Books, pp. 73-90.

DWORKIN, Ronald. 2010. Pluralismo moral. In: DWORKIN, Ronald. A Justiça de toga. São Paulo: Martins Fontes, pp. 149-165.

GALSTON, William. 2002. Liberal pluralism: the implication of value pluralism for political theory and practice. Cambridge: Cambridge University Press.

GRAY, John. 2000a. Two faces of liberalism. London: Polity.

GRAY, John. 2000b. Isaiah Berlin. São Paulo: Difel.

GRAY, John. 2000c. Pluralism and toleration in contemporary political philosophy. Political Studies, v. 48, pp. 323-333.

HART, H. L. A. 1997. Are there any natural rights? In: Goodin, Robert E.; Pettit, Philip (ed.). Contemporary political philosophy: an anthology. London: Blackwell, pp. 281-288.

HART, H. L. A. 2012. Leis, comandos e ordens. In: HART, Herbert Lionel Adolphus. O conceito de direito. São Paulo: Martins Fontes, pp. 24-33.

HAYEK, F. A. 1981. Os fundamentos da liberdade. Brasília: UnB.

KEKES, John. 1993. The morality of pluralism. Princeton: Princeton University Press.

MACPHERSON, C. B. 1973. Berlin's division of liberty. In:

MACPHERSON, C. B. Democratic theory: essays in retrieval. Oxford: Clarendon Press, pp. 95-119. 
MIGUEL, Luis Felipe. 2015. O liberalismo e o desafio das desigualdades. In: MIGUEL, Luis Felipe. Desigualdades e democracia: o debate da teoria política. São Paulo: Unesp, pp. 25-66.

NUSSBAUM, Martha C. 2000. Women and human development: the capabilities approach. Cambridge: Cambridge University Press.

PERELMAN, Chaim. 2004. Introdução: lógica jurídica e nova retórica. In: PERELMAN, Chaim. Lógica jurídica. São Paulo: Martins Fontes, pp. 1-29. PETTIT, Philip. 2011. The instability of freedom as noninterference: the case of Isaiah Berlin. Ethics, v. 121, n. 4, pp. 693-716.

SILVA, Ricardo. 2011. Republicanismo neo-romano e democracia contestatória. Revista de Sociologia e Política, v. 19, n. 39, pp. 35-51.

SILVA, Ricardo. 2015. Visões da liberdade: republicanismo e liberalismo no debate teórico contemporâneo. Lua Nova, n. 94, pp. 181-215.

VITA, Alvaro de. 2011. Liberalismo, justiça social e responsabilidade individual. Dados, v. 54, n. 4, pp. 569-608. 


\section{LEI, LIBERDADE E DIVERSIDADE DE FINS NO PLURALISMO DE VALORES}

\section{IVO COSER}

Resumo: $\mathrm{O}$ artigo analisa a relação entre a ideia de lei e de liberdade no pluralismo de valores. A partir da obra de Isaiah Berlin são apresentadas três concepções de lei: a lei como intervenção arbitrária, a lei como não interferência e a lei como uma intervenção moralmente aceita. A primeira se manifestaria quando a lei força sem motivos justos os sujeitos a uma ação. É esta ideia que fornece sentido à frase de Berlin: "toda lei é uma infração da liberdade”. A segunda corresponde ao enfoque libertarista, que Berlin critica porque destrói a liberdade de escolha. Por último, o artigo aponta que o pluralismo de valores concilia a ideia de lei como uma intervenção com o conceito de liberdade. Palavras-chave: Pluralismo de Valores; Lei; Liberdade; Isaiah Berlin.

\section{LAW, FREEDOM AND DIVERSITY OF ENDS IN THE VALUE PLURALISM}

Abstract: The article analyzes the relation between the idea of law and freedom in the Value Pluralism. From Isaiah Berlin's work, the article presents three conceptions of law: the law as arbitrary intervention, the law as non-interference and the law as a morally accepted intervention. The first one occurs when the law unfairly forces the subjects to an action. It is this idea that gives meaning to Berlin's phrase: "every law is a violation of freedom". The second one corresponds to the libertarian approach, which Berlin criticizes because it destroys freedom of choice. Finally, the article points out that Value Pluralism reconciles the idea of law as an intervention with the concept of freedom.

Keywords: Value Pluralism; Law; Freedom; Isaiah Berlin.

Recebido: 31/10/2018 Aprovado: 16/07/2019 